\title{
FY09 PROGRESS: MULTI-ISOTOPE PROCESS (MIP) MONITOR
}

\author{
JM Schwantes \\ CG Fraga \\ CR Orton \\ A Laspe \\ RN Christensen \\ $\mathrm{R}$ Ward
}

October 2009

\section{Pacific Northwest}

NATIONAL LABORATORY

Proudly Operated by Battelle Since 1965 




\title{
DISCLAIMER
}

This report was prepared as an account of work sponsored by an agency of the United States Government. Neither the United States Government nor any agency thereof, nor Battelle Memorial Institute, nor any of their employees, makes any warranty, express or implied, or assumes any legal liability or responsibility for the accuracy, completeness, or usefulness of any information, apparatus, product, or process disclosed, or represents that its use would not infringe privately owned rights. Reference herein to any specific commercial product, process, or service by trade name, trademark, manufacturer, or otherwise does not necessarily constitute or imply its endorsement, recommendation, or favoring by the United States Government or any agency thereof, or Battelle Memorial Institute. The views and opinions of authors expressed herein do not necessarily state or reflect those of the United States Government or any agency thereof.

\author{
PACIFIC NORTHWEST NATIONAL LABORATORY \\ operated by \\ BATTELLE \\ for the \\ UNITED STATES DEPARTMENT OF ENERGY \\ under Contract DE-AC05-76RL01830
}

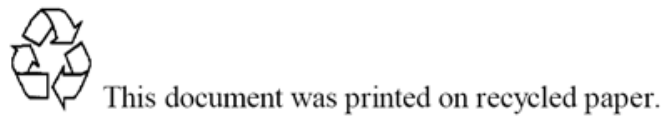

(9/2003) 
FY09 PROGRESS: MULTI-ISOTOPE PROCESS (MIP) MONITOR Jon Schwantes ${ }^{1}$, Christopher Orton ${ }^{1,2}$, Carlos Fraga ${ }^{1}$, Richard Christensen ${ }^{2}$, Amy Laspe ${ }^{3}$, Rebecca Ward $^{4}$

${ }^{1}$ Advanced Radioanalytical Chemistry Group, National Security Directorate, Pacific Northwest National Laboratory, Richland, Washington

${ }^{2}$ Professor, Nuclear Engineering Department, The Ohio State University, Columbus.

${ }^{3}$ NSIP Student Intern, University of Wisconsin, Madison.

${ }^{4}$ NSIP Student Intern, University of Texas, Austin.

\section{INTRODUCTION}

Modern industrial reprocessing techniques, including the PUREX and UREX+ family of separations technologies, are based on solvent extraction between organic and aqueous phases. In these bi-phase systems, product (actinide) and contaminant (fission and activation products) elements are preferentially driven (thermodynamically) to opposite phases, with small amounts of each remaining in the other phase. ${ }^{1}$

The distribution of each element, between the organic and aqueous phases, is determined by major process variables such as acid concentration, organic ligand concentration, reduction potential, and temperature. Hence, for consistent performance of the separation process, the distribution of each element between the organic and aqueous phases should be relatively constant. During "normal" operations the pattern of elements distributing into the product and waste streams at each segment of the facility should be reproducible, resulting in a statistically significant signature of the nominal process conditions. Under "abnormal" conditions, such as those expected under some protracted diversion scenarios, patterns of elements within the various streams would be expected to change measurably.

The MIP monitoring approach utilizes changes in the concentrations of gamma-emitting elements as evidence of changes to the process chemistry. ${ }^{2,3,4}$ It exploits a suite of gamma emitting isotopes to track multiple chemical species and behaviors simultaneously, thus encompassing a large array of elements that are affected by chemical and physical changes. In-process surveillance by the MIP monitor is accomplished by coupling the gamma spectrometry of the streams with multivariate techniques, such as Principal Component Analysis (PCA). PCA is a chemometrics tool that finds combinations of variables (principal components or PCs) that best describe the common variance between differing datasets. ${ }^{5}$ Using multivariate analysis, such as PCA, the MIP monitoring technique is then capable of automatically evaluating the patterns of the gamma-emitting contaminants for statistically relevant signs of potential changes to the process chemistry. The MIP monitor represents the first of its technology to combine gamma-ray spectroscopy with multivariate analysis for monitoring reprocessing operations.

\section{METHODOLOGY}

Methodology of the Simulations

A group of three computer models were used to simulate gamma spectra from reprocessing streams to test the MIP monitor concept. Spent boiling water reactor (BWR) fuel was modeled using ORIGENARP. ${ }^{6}$ The fuel was modeled with various burnup levels for comparison purposes. The fuel type selected in ORIGEN-ARP (which includes the cross section libraries) was General Electric BWR fuel with 3\% enrichment.

As output, ORIGEN-ARP provides quantity, weight, and activity of the elements and isotopes in the fuel. This output was used as a basis for predicting the elemental and isotopic composition in a simulated dissolved fuel solution. The results from the ORIGEN-ARP simulation were used as input for Argonne's Model for Universal Solvent Extraction (AMUSE) ${ }^{7,8,9}$ code to simulate solvent extraction. AMUSE, in its entirety, can calculate the steady state compositions for both the aqueous and organic phases at each contactor stage for various processes as well as estimate the size and cost of the necessary equipment. For the purposes of this study, only a portion of the code (Spreadsheet Algorithm for Speciation and Partitioning Equilibria, SASPE) was used to calculate the batch extraction distribution coefficient for the primary uranium and plutonium extraction in a PUREX process. Regalbuto et. al. ${ }^{7}$ 
explain that SASPE uses input compositions and the conditions of the aqueous and organic phases to calculate the distribution ratios. These calculations employ chemically correct models that use the thermodynamic activities of the major aqueous species. The approach of Bromley ${ }^{10}$ is used to calculate these activities from aqueous-phase compositions. Solvent loading is also incorporated into the distribution coefficient.

An aqueous feed solution with a standard uranium concentration of $1.3 \mathrm{M}$ for a typical PUREX process was modeled. ${ }^{11}$ Concentrations of major radioactive fission products were included in accordance to their respective ratios to the uranium in the dissolved fuel as simulated by ORIGEN-ARP. All fission and activation products were assumed to have dissolved completely into solution. The total element concentration of the selected nuclides were entered into AMUSE and the distribution coefficient was calculated based on simulated contact with a 30\% (V/V) Tri-Butyl Phosphate (TBP) in dodecane in a two-to-one volume ratio with the aqueous phase. The distribution coefficients were calculated at different nitric acid concentrations of the feed solution.

The output from AMUSE consisted of the distribution coefficients for each element. Elements included in AMUSE defined by the default distribution coefficient included barium (Ba), carbon (C), cadmium (Cd), and cesium (Cs). In addition, the palladium (Pd) distribution coefficients as a function of acid concentration from literature ${ }^{12}$ were used instead of the default constant. The input to AMUSE assumed that all of the plutonium existed in the IV oxidation state. This assumption was adequate since the gamma rays from Pu did not add appreciably to the overall spectra of spent fuel. AMUSE did not have the capability to model distribution coefficients for Antimony (Sb), Tellurium (Te), Tin (Sn), Nickel $(\mathrm{Ni})$, and Niobium $(\mathrm{Nb})$. These elements were left out of the model simulations.

The distribution coefficients generated by AMUSE were used to derive the element concentrations in both the organic extract and aqueous raffinate solutions. The fraction of each element extracted combined with its relative isotopic abundances from ORIGEN-ARP output were used to distribute the nuclide activity between phases and propagate a list of nuclides and their activity. The nuclide activity list was used as source characterization for input into a third computer program, PNNL's Synth code, ${ }^{13}$ to simulate gamma spectra of the feed, raffinate and organic extract solutions. Synth is a 1$\mathrm{D}$ radiation transport code designed to mimic the response of a selected detector type among several choices, including sodium iodide (NaI), high purity germanium (HPGe) and cadmium zinc telluride (CZT) crystals. Spectra are populated based on the nuclide source list and a library that attributes the gamma-rays and their branching ratios to each nuclide. Here, the gamma spectrum from the dissolver and the organic extract were simulated using HPGe.

For all spectral simulations, a point source was assumed. For the acid concentration variations, the energy calibration was set to $0.5 \mathrm{keV}$ per channel and 4096 channels were used, resulting in full scale energy of $2048 \mathrm{keV}$. The live time was set to one hour and the source was located 5 centimeters from the detector. For the direct measurement of dissolver solutions, the detector was modeled with $0.3 \mathrm{keV}$ per channel with 8192 channels resulting in an energy scale up to $2457 \mathrm{keV}$. The count time was ten minutes and the source was located 10 centimeters from the detector. The HPGe detector was a coaxial model with $50 \%$ efficiency and the default settings were used, including a resolution of $1.9 \mathrm{keV}(0.14 \%)$ at 1332 $\mathrm{keV} .^{13}$ These gamma spectra for the organic extract and aqueous dissolver were simulated as a function of acid concentration and burnup level, respectively.

\section{Methodology of the Experiment}

A segment of boiling water reactor (BWR) spent commercial nuclear fuel were used in the experimental analysis of the MIP monitor. The dissolution and separation of the fuel was performed at the Shielded Analytical Laboratory hot cell facility at Pacific Northwest National Laboratory.

The segment of fuel used in the experiment was part of the ATM 109 fuel rod group, which was BWR fuel irradiated in the Quad Cities I reactor. This rod was fabricated by GE, post-irradiation examinations were performed at GE's Vallecitos Nuclear Center, and then the fuel was sent to Argonne National Laboratory (ANL) followed by Pacific Northwest National Laboratory (PNNL) for use as an Approved Testing Material. The segment of fuel dissolved for the demonstration had an initial 
enrichment of 3\% and a burnup level of approximately 67 - $70 \mathrm{MWd} / \mathrm{kgU}$. The fuel was irradiated from February 1979 until September 1987 at which point the rod was removed from its bundle and placed in a carrier assembly. The carrier assembly was placed back into the reactor and the rod was irradiated from November 1989 until September 1992. ${ }^{14,15}$ As of September 2009, the fuel had been cooling for approximately 17 years.

The dissolution and extraction of the fuel segment was performed in a hot cell by manipulators. The segment was removed from its cladding (12 - 15 grams) and dissolved in concentrated nitric acid. The undissolved fines were removed by centrifuging the solution. A total of five feed/dissolver samples were prepared for solvent extraction by a TBP and dodecane mixture. Each of these feed solutions had a uranium concentration of roughly $0.7 \mathrm{M}$ and nitric acid concentrations of approximately $0.3,1.3,2.5,3.8$ and $5.1 \mathrm{M}$, respectively. Following dissolution, each of the fuel segments underwent the first stage of a PUREX-type extraction in batch wise fashion. These aqueous samples were mixed with an equal volume of 30\% (V/V) Tri-Butyl Phosphate (TBP) in dodecane solution and then centrifuged to separate the phases. Portions of the feed, aqueous raffinate and organic extract were removed and stored for analysis.

The samples were removed from the hot cell for additional preparation and analysis. The solutions were sub-sampled to reduce the gross amount of radiation emitted by each sample. Portions $(0.1 \mathrm{~mL})$ of each sample were placed in $4 \mathrm{~mL}$ glass vials and diluted to $1 \mathrm{~mL}$ with $0.5 \mathrm{M}$ nitric acid (aqueous samples) or 30\% (V/V) TBP in dodecane (organic samples) in order to provide sufficient volume to facilitate collimation during counting. In the case of the organic samples, the radiation levels of the undiluted samples were already low, but the sub-sampling during dilution further eliminated any aqueous carry over incompletely separated in the hot cell.

Gamma counting was performed in the Radiological Process Laboratory using a high purity germanium (HPGe) detector. The organic samples were counted on either a $70 \%$ or a $74 \%$ relative efficiency Ge detector at close range for a total live count time of two hours. Calibrations, performed on the detector daily, showed minimal drift (approximately $\pm 0.1 \mathrm{keV}$ ).

All samples were counted at least once. The five organic extract samples were also counted 10 times each in a random order, resulting in additional spectra for use with PCA.

\section{Multivariate Analysis Techniques}

Several multivariate analyses were performed on the data set for each detector, including Hierarchical Cluster Analysis (HCA), Principle Component Analysis (PCA), and the Partial Least Squares (PLS) method. The PLS Toolbox ${ }^{16}$ for Matlab ${ }^{17}$ was used to perform all of the multivariate analyses mention above. All of the techniques required data preprocessing before they could be applied. In our case, preprocessing consisted of normalization to unit area and mean-centering. Normalizing by area removes the effect of source intensity on the spectra while maintaining the pattern. Though intensity is a valid indicator of fuel history or process conditions, it is also easily influenced by source/detector geometry. While this effect can be easily managed during simulations, it may be difficult to control size and geometry of the samples to maintain precision between samples during an actual deployment. Normalization should reduce these artificial pattern variances. Because normalization would be used in an actual deployment, it was used exclusively for the first step of the simulated data preprocessing.

The analysis of the spectra included both supervised and unsupervised pattern recognition. Supervised pattern recognition takes into account sample information, such as which samples are normal and which are off-normal, in order to establish groups of interest and compare new samples to the groups. Unsupervised pattern recognition does not consider the sample's origins, but instead allows the samples to group based solely on the similarities and differences found in the spectra. This allows the intrinsic organization to emerge resulting in increased insight into the reaction of the samples to the analysis technique.

After analysis by PCA, PLS method was applied to the organic extract spectra to predict the acid concentration of the fuel represented by the spectra. PLS is a multivariate calibration method that uses an approach analogous to PCA. The general version of PLS described and used in this manuscript is PLS1. 
18 Using PLS1, it is necessary to develop separate models for each property of interest (i.e., burnup level or acid concentrations) to extract quantitative information.

\section{RESULTS}

\section{Non-Optimized Experimental Estimation of MIP Monitor for Determining Acid Concentration}

The first stage of a PUREX type extraction was applied to dissolved spent fuel at the Hot Cell facility at PNNL. The organic phase after extraction was removed from the hot cells and counted using a HPGe detector. Figure 1 shows typical spectra from the organic phase as a function of the acid concentration of the aqueous feed solution. These spectra were mean centered normalized and analyzed using unsupervised PCA. Results from these analyses (shown in Figure 2) illustrate that spectra can be grouped according to acid concentration. Nine replicates at each acid concentration were then used to generate a supervised and calibrated (PLS) PCA model. One replicate at each acid concentration was then treated as an unknown and superimposed on the model to test the ability of the model to predict their acid concentration (Figure 3). The root mean squared error of the prediction (RMSEP) is shown in the figure, which is an estimate of the performance of this approach. These preliminary results were limited by two major factors: (1) the number of experimental samples available; (2) the linear nature of the PLS model used to predict a nonlinear system. Considering these limitations, this approach was able to predict acid concentration of the feed from the experimental gamma spectra of the organic phase following extraction to within $\pm 0.1 \mathrm{M}$ at three sigma.

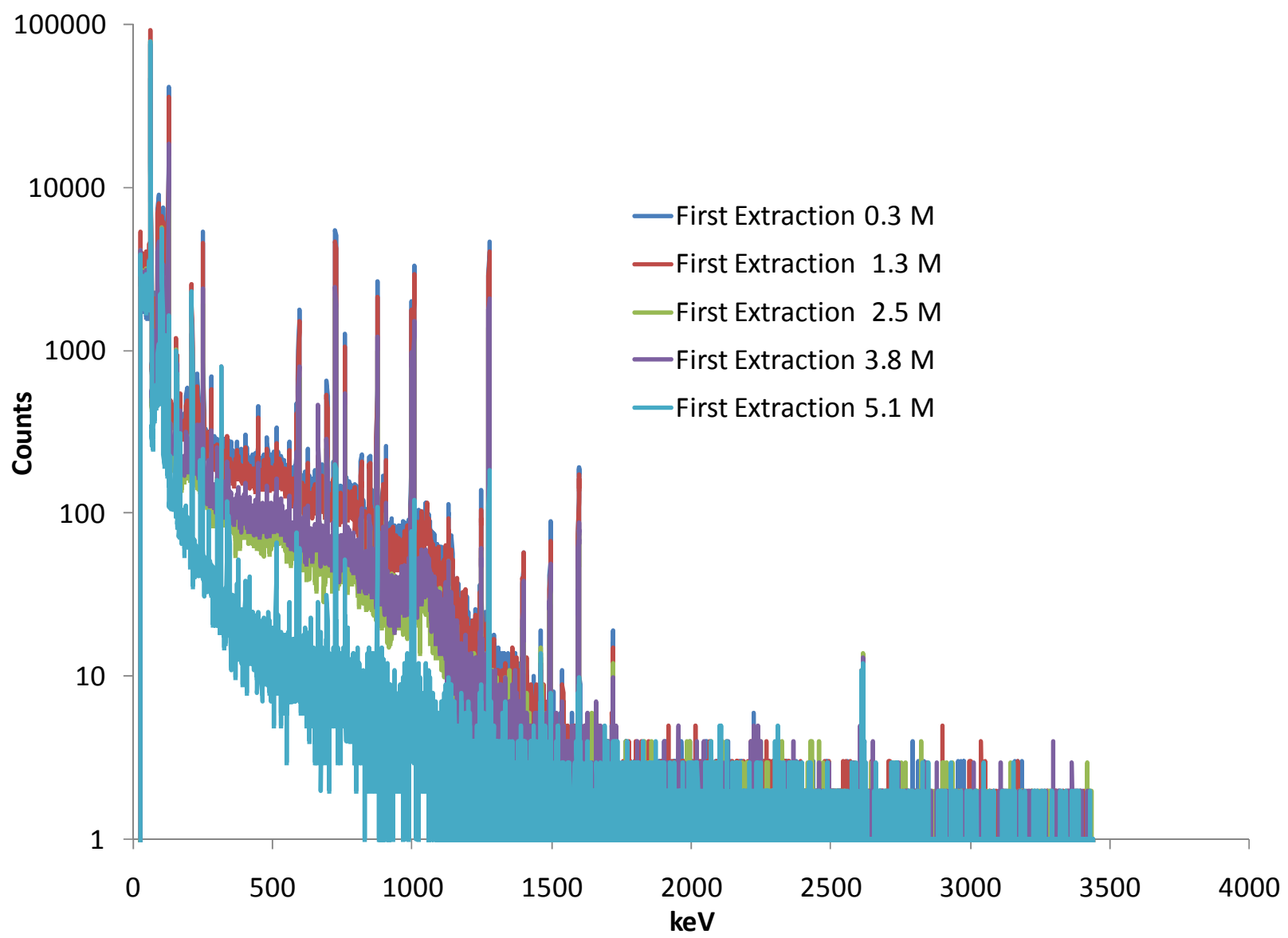

Figure 1. Simulated gamma spectra generated from High Purity Ge detector for BWR fuel 69-70 $\mathrm{MWd} / \mathrm{kgU}, 16$ years cooled, as a function of acid concentration. 


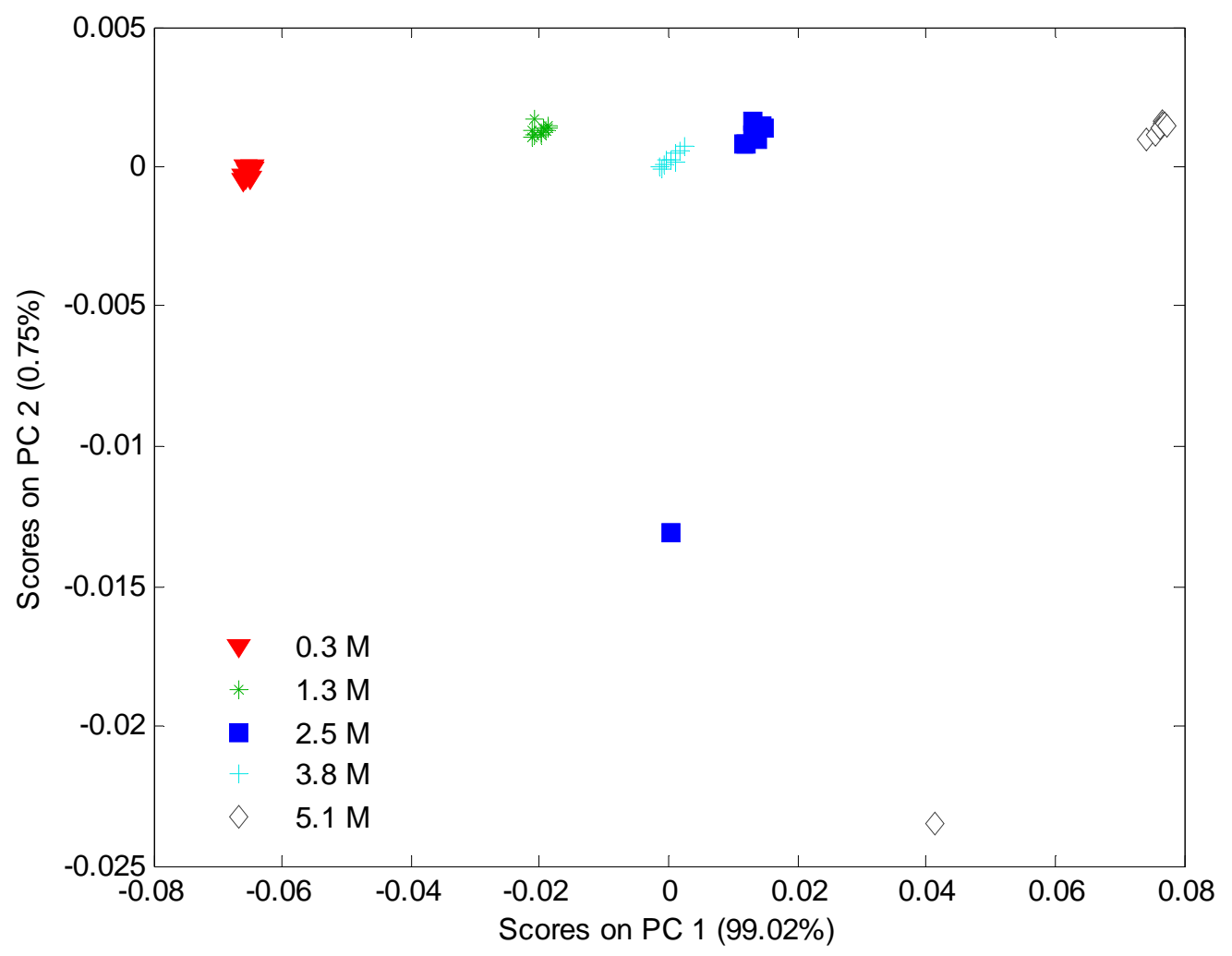

Figure 2. PCA grouping of above spectra.

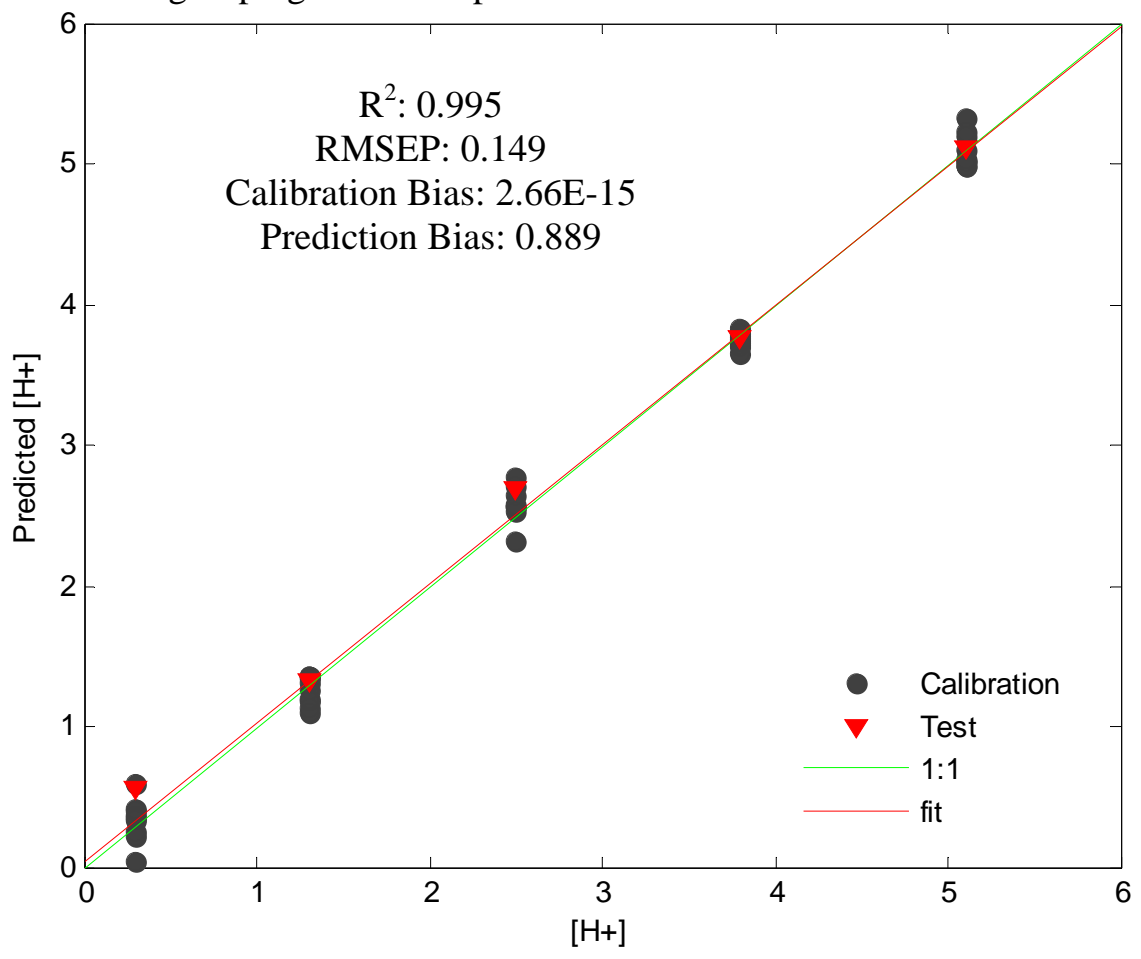

Figure 3. PLS model results generated from data shown in Figure 2. 


\section{Simulated Sensitivity of the MIP Monitor for Monitoring Acid Concentration}

Simulations designed to mimic experimental investigations described above were conducted. Figure 4 shows simulated spectra from the organic phase as a function of the acid concentration of the aqueous feed solution. These spectra were mean centered normalized and analyzed using PLS. Five of these spectra were used to generate a supervised and calibrated (PLS) PCA model. The remaining two spectra were used as unknowns to test the predictive capability of the model (Figure 5). The RMSEP is shown in the figure, which is an estimate of the performance of this approach. These simulations suggest the MIP approach, once optimized for a linear PLS model, may be able to predict the acid concentration of the feed using gamma spectra of the organic phase following extraction to within $\pm 0.05 \mathrm{M}$. Data points in Figure 5 show some level of nonlinearity, suggesting that a nonlinear model may be more accurate and appropriate for this application.

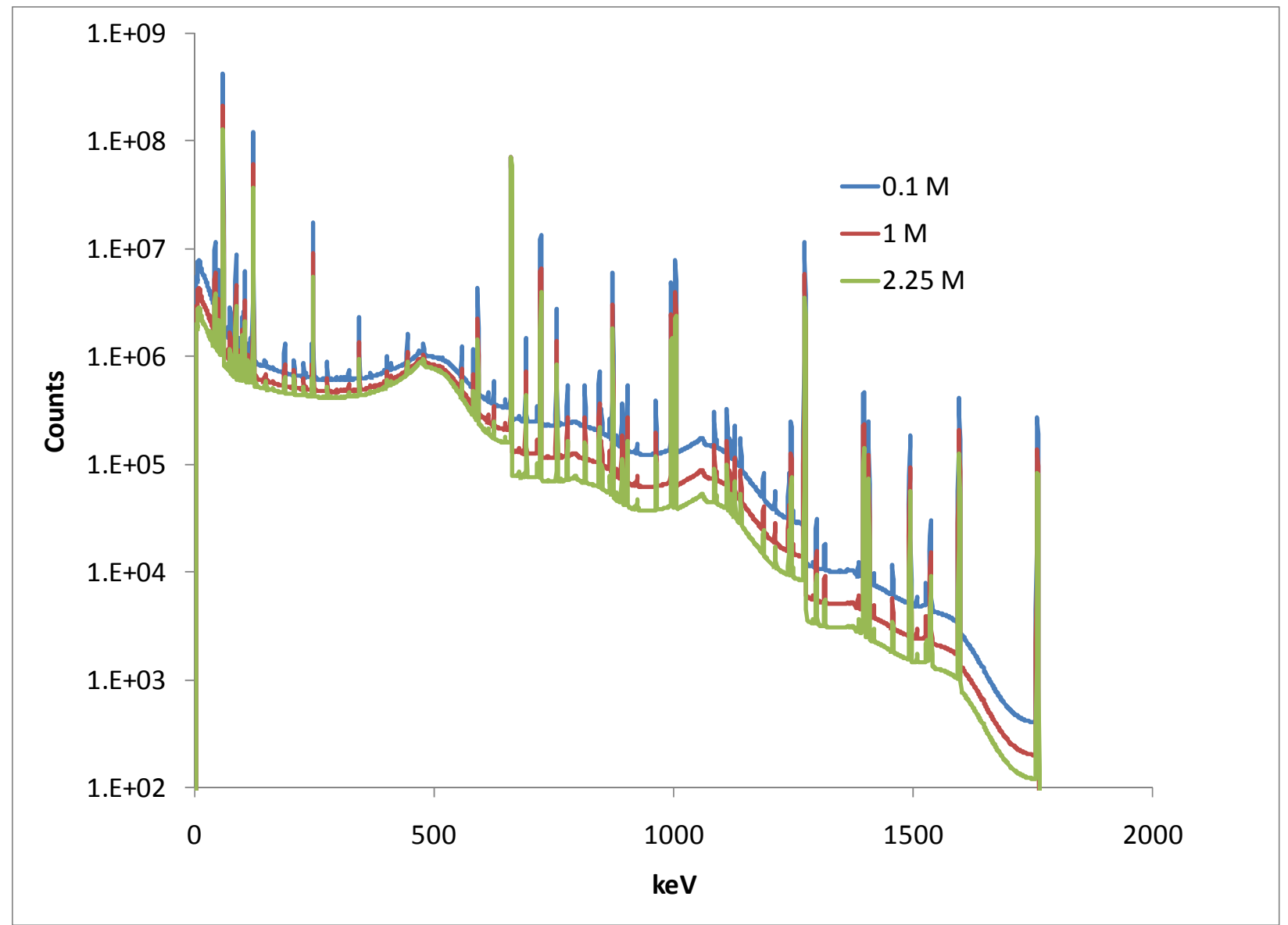

Figure 4. Simulated gamma spectra generated from High Purity Ge detector as a function of acid concentration for spent BWR fuel (16 MWd/kgU, 26 year cooling). 


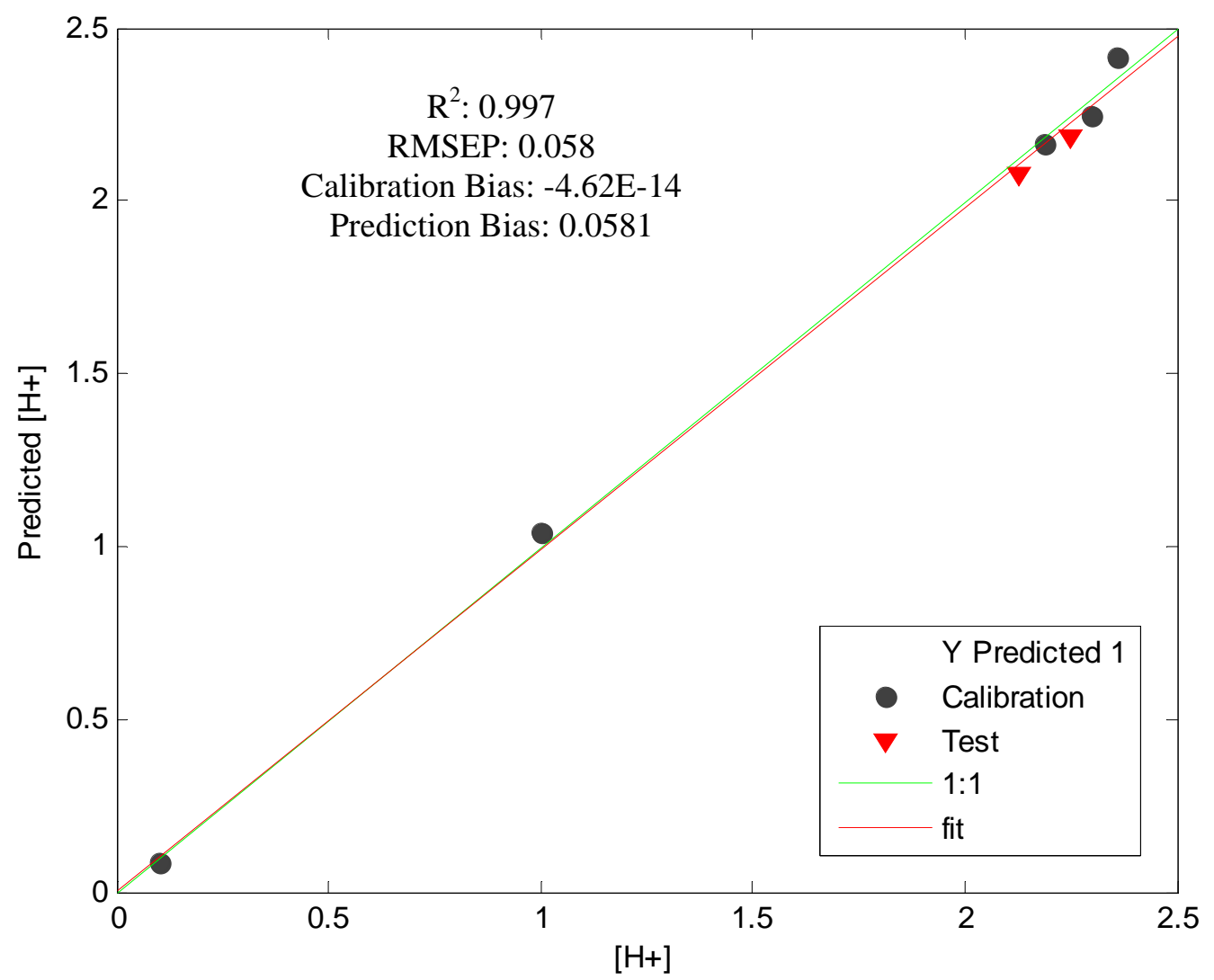

Figure 5. PLS model results from spectra shown in Figure 4. 


\section{Simulated Sensitivity of the MIP Monitor for Determination of Burnup}

Traditional gamma spectrometry has been employed in the past to estimate burnup. However, this technique typically relies on the measurement of the $661 \mathrm{keV}{ }^{137} \mathrm{Cs}$ line, which in turn depends upon an accurate estimate of the baseline underneath this peak. We hypothesized that the MIP approach may provide a better estimate of burnup by utilizing multiple indicator peaks and more accurately accounting for the unresolved baseline. This hypothesis was tested using simulated gamma spectra of three-year cooled, dissolved, spent fuel taken from a fictitious dissolver tank (shown in Figure 6) as a function of burnup. In all, nine spectra were generated from simulations. These spectra were mean centered and normalized and then analyzed using unsupervised PCA. Six spectra were then used to generate a supervised and calibrated (PLS) PCA model, while three spectra were treated as unknowns and used to test the model predictive capability. The model developed from spectra that were mean centered and normalized (Figure 7) was found to be less accurate than the model based on spectra that simply were mean centered before use (Figure 8), indicating intensity was an important determinant in model output. The RMSEP is shown in each of the figures. These results suggest the MIP approach could be used to estimate burnup at the dissolver tank to within $\pm 0.1 \%$ of the actual burnup. Model estimates of the MIP performance for this type of application need to be confirmed through experiments.

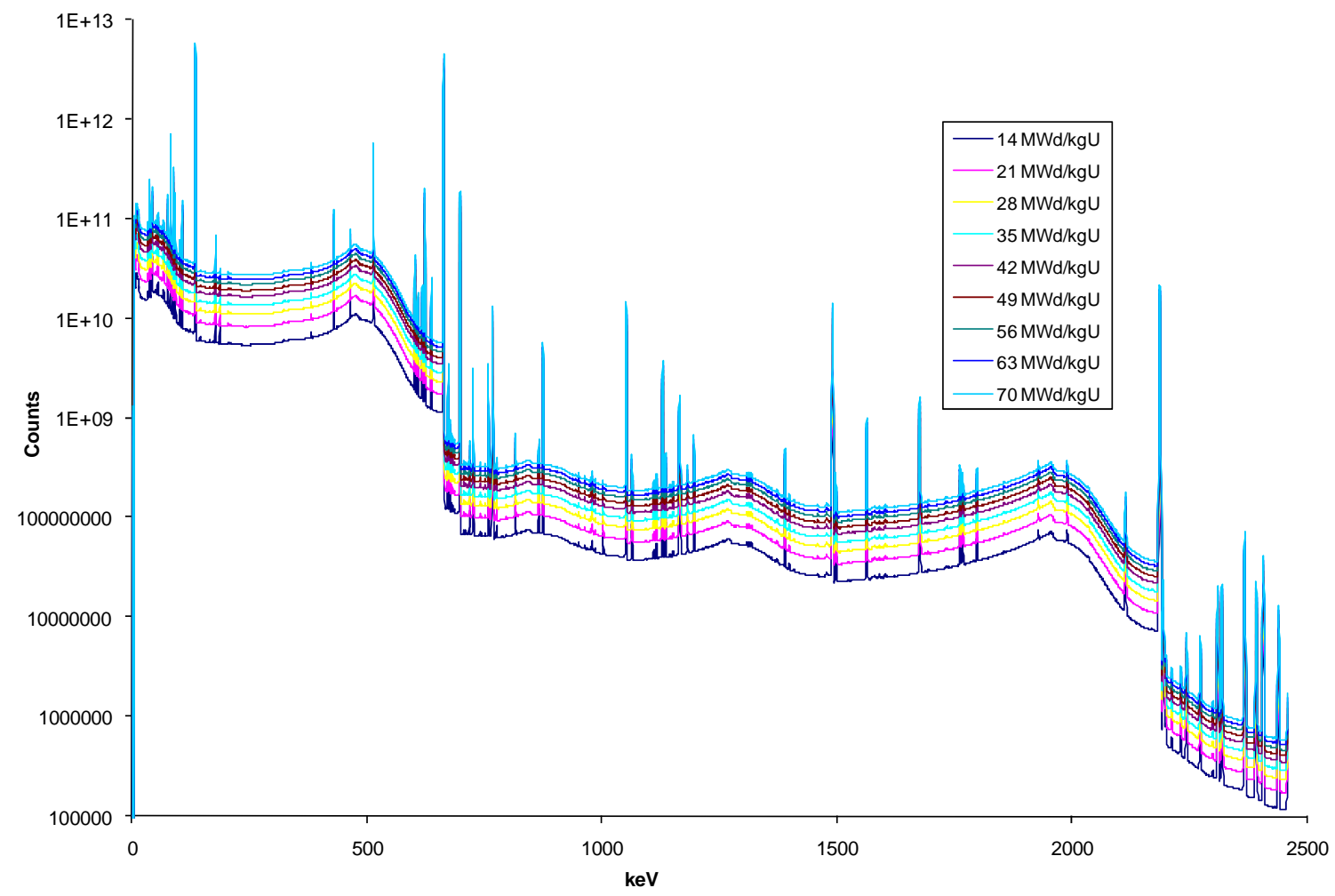

Figure 6. Simulated gamma spectra of 3-year cooled dissolved spent fuel as a function of burnup, generated from High Purity Ge detector. 


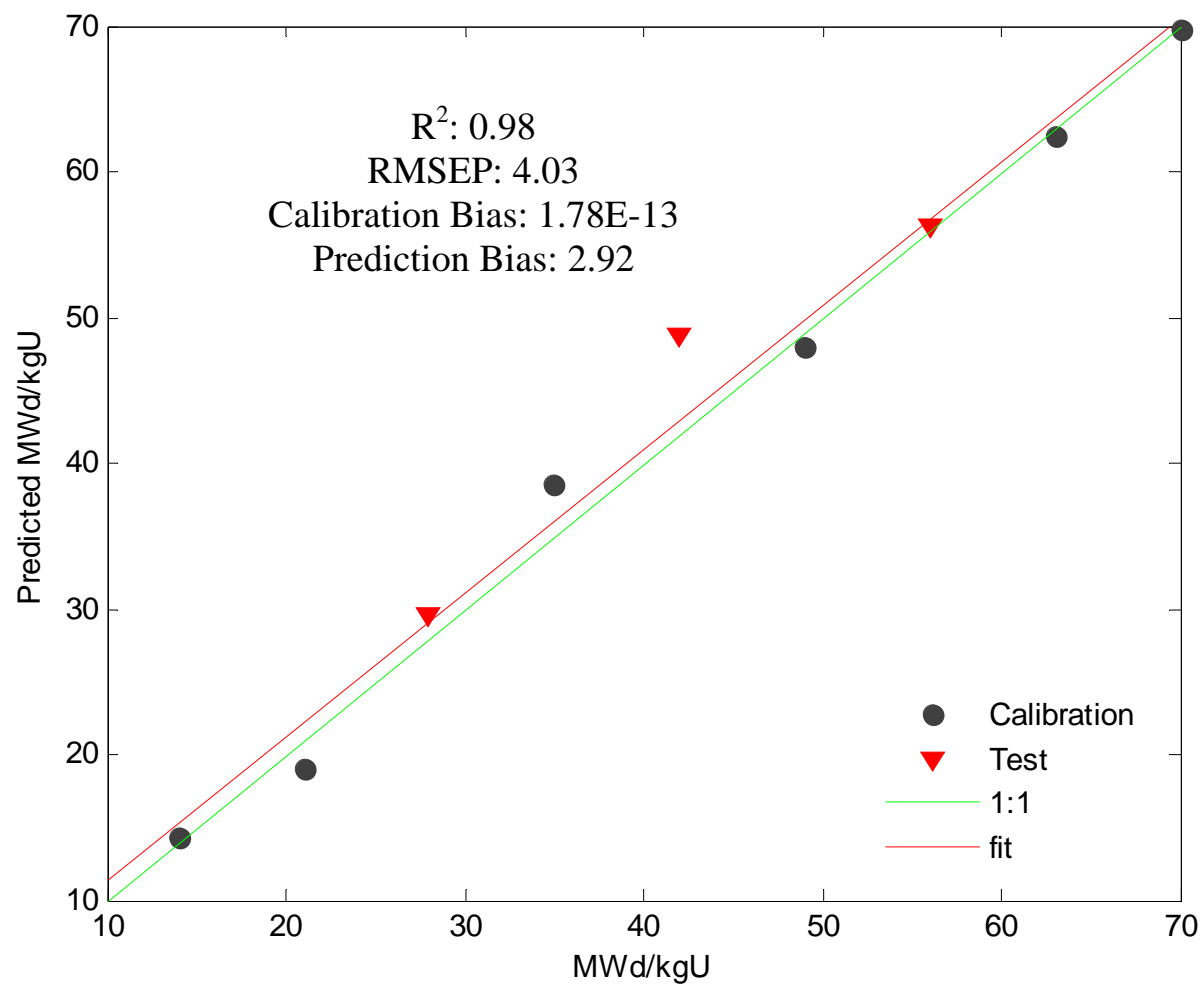

Figure 7. PLS model results generated from spectra shown in Figure 6 after mean centering and normalization.

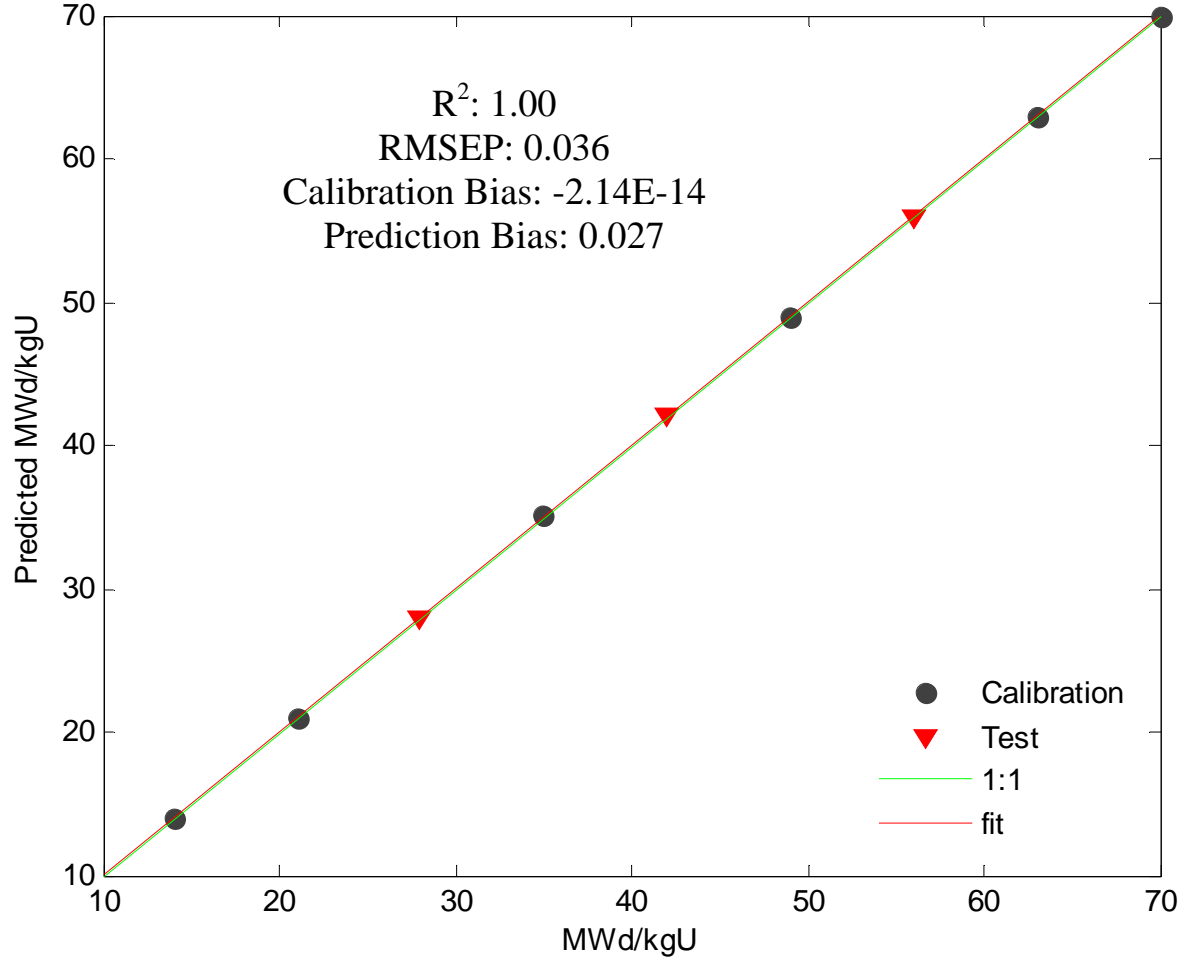

Figure 8. PLS model results generated from spectra shown in Figure 6 after mean centering. 


\section{REFERENCES}

\footnotetext{
${ }^{1}$ M. Benedict, T.M. Pigford, and H.W. Levi. Nuclear Chemical Engineering, $2^{\text {nd }}$ Ed. McGraw-Hill, New York, NY (1981).

${ }^{2}$ L.E. Smith, J.M. Schwantes, J.J. Ressler, M. Douglas, K.A. Anderson, C.G. Fraga, P.C. Durst, C.R. Orton, R.N. Christensen. "Next Generation On-line MC\&A Technologies for Reprocessing Plants” Proceedings of Global 2007 Conference on Future Nuclear Energy Systems, 2007

${ }^{3}$ J.M. Schwantes, M. Douglas, C.R. Orton, C. Fraga and R.N. Christensen. "Multi-Isotope Process (MIP) Monitor: a Near-Real-Time Monitor for Reprocessing Facilities” ANS Transactions from the Annual Meeting, Anaheim, CA, 2008.

${ }^{4}$ C.R. Orton, J.M. Schwantes, S. Bryan, T. Levitskaia, D. Duckworth, M. Douglas, O.T. Farmer, C. Fraga, S. Lehn, M. Liezers, S. Peper, R.N. Christensen. "Advanced Safeguards Technology Demonstration at Pacific Northwest National Laboratory" Proceedings of the $49^{\text {th }}$ Annual INMM Conference, Nashville, TN, 2008

${ }^{5}$ E. Malinowski. Factor analysis in chemistry, John Wiley \& Sons, New York, NY, 405p (2008).

${ }^{6}$ A.G. Croff. "ORIGEN2: A versatile computer code for calculating the nuclide compositions and characteristics of nuclear materials”, Nucl. Technol., 62, 3, 1983.

${ }^{7}$ M. C. Regalbuto, J. M. Copple, R. Leonard, C. Pereira, G. F. Vandegrift “Solvent Extraction Process Development for Partitioning and Transmutation of Spent Fuel" Proceeding of the $8^{\text {th }}$ Information Exchange Meeting on Actinide and Fission Product Partitioning and Transmutation:, Las Vegas, Nevada, United States, November 9-1, pp. 373-385, 2004; (C) Organization for Economic Co-operation and Development, Nuclear Energy Agency (OECD-NEA): Paris, France, 2005, accessed at http://www.nea.fr/html/pt/docs/iem/lasvegas04/posterI.html (October 2009).

${ }^{8}$ G.F. Vandegrift, D.B. Chamberlain, C. Conner, J.M. Copple, J.A. Dow, L. Everson, J.C. Hutter, R.A. Leonard, L. Nunez, M.C. Regalbuto, J. Sedlet, B. Srinivasan, S. Weber, and D.G. Wygmans. "Development and Demonstration of the TRUEX Solvent Extraction Process," Proceedings of the Symposium on Waste management, Tucson, AZ, Feb. 28-Mar. 4, 1993, pp. 1045-1050.

${ }^{9}$ R.A. Leonard and M.C. Regalbuto "A Spreadsheet Algorithm for Stagewise Solvent-Extraction,", Solvent Extraction and Ion Exchange, Vol. 12, Issue 5, pp 909 - 930, 1994.

${ }^{10}$ L.A. Bromley. "Thermodynamic Properties of Stroping Electrolytes in Aqueous Solutions.” AIChE J., 19, 313, 1973.

${ }^{11}$ M. Benedict, T.M. Pigford, and H.W. Levi. Nuclear Chemical Engineering, $2{ }^{\text {nd }}$ Ed. McGraw-Hill, New York, NY, 1981.

${ }^{12}$ T. Ishimori and K. Watanabe. "Inorganic Extraction Studies on the System of Tri-n-butyl Phosphate-Nitric Acid.” Bulletin of the Chemical Society of Japan, Vol. 33, No. 10, 1960.

${ }^{13}$ W.K. Hensley, A.D. McKinnon, H.S. Miley, M.E. Panisko, and R.M. Savard, “SYNTH: a spectrum synthesizer," J. Radioanal. Nucl. Chem., 193, 229, 2005.

${ }^{14}$ Vaidyanathan, S., Reager, R.D., Warner, R. W. et al. "High Burnup BWR Fuel Pellet Performance.” American Nuclear Society, Proceedings of the International Topical Meeting on Light Water Reactor Fuel Performance (p. 471), Portland, OR, March 2-6, 1997.

${ }^{15}$ S.F. Wolf, D.L. Bowers, J.C. Cunnane. “Analysis of high burnup spent nuclear fuel by ICP-MS.” Journal of Radioanalytical and Nuclear Chemistry, Vol. 263, No. 3, p. 581-586 (2005).

${ }^{16}$ PLS_Toolbax Version 5.0 for use with MATLAB, Eigenvector Research, Inc, Wenatchee, WA. 2008.

${ }^{17}$ Matlab, Ver. 7.8.0.347 (R2009a), The MathWorks, Inc, 2009.

${ }^{18}$ B.M. Wise et al. PLS Toolbax Version 4.0 for use with MATLAB, Manual. Eigenvector Research, Inc, Wenatchee, WA. 2006.
} 